\title{
NDNF variants are rare in patients with congenital hypogonadotropic hypogonadism
}

\author{
Satoshi Tamaoka', Erina Suzuki ${ }^{1}$, Atsushi Hattori', Tsutomu Ogata $\mathbb{C}^{2}$, Maki Fukami (i] ${ }^{1}$ and Yuko Katoh-Fukui ${ }^{1}$
}

\begin{abstract}
Although NDNF was recently reported as a novel causative gene for congenital hypogonadotropic hypogonadism $(\mathrm{CHH})$, this conclusion has yet to be validated. In this study, we sequenced NDNF in 61 Japanese CHH patients. No variants, except for nine synonymous substitutions that appear to have no effect on splice-site recognition, were identified in NDNF coding exons or flanking intronic sequences. These results indicate the rarity of NDNF variants in $\mathrm{CHH}$ patients and highlight the genetic heterogeneity of $\mathrm{CHH}$.
\end{abstract}

Congenital hypogonadotropic hypogonadism $(\mathrm{CHH})$ is a rare condition that results in hypomasculinization of male neonates and delayed puberty in children of both sexes ${ }^{1}$. $\mathrm{CHH}$ occurs as a component of malformation syndromes, such as Kallmann syndrome (MIM: 308700, 614897, and 613301), CHARGE syndrome (MIM: 214800), and septooptic dysplasia (SOD) (MIM: 182230), though it can also manifest as an isolated endocrine disorder ${ }^{1}$. To date, more than 30 genes have been implicated in $\mathrm{CHH}$; however, pathogenic variants in these genes together account for only approximately half of all cases ${ }^{1}$. This suggests that other genes are also involved in the development of $\mathrm{CHH}$. In 2020, Messina et al. performed whole-exome sequencing for 240 unrelated $\mathrm{CHH}$ patients mostly of European origin and identified four apparently pathogenic variants in NDNF (NM_024574.4) (p. Lys62*, p. Tyr128Thrfs"55, p. Trp469*, and $\mathrm{p}$. Thr201Ser) in four patients ${ }^{2}$. The four patients presented with Kallmann syndrome and carried no pathogenic variants in other known $\mathrm{CHH}$-causing genes. Moreover, the four NDNF variants were shared by family members who exhibited anosmia/hyposmia or delayed puberty. Furthermore, the authors showed that neuron-derived neurotrophic factor, which is encoded by $N D N F / N d n f$, is involved in the survival, migration, and growth of neurons in mice. These

\footnotetext{
Correspondence: Maki Fukami (fukami-m@ncchd.go.jp)

'Department of Molecular Endocrinology, National Research Institute for Child Health and Development, Tokyo, Japan

${ }^{2}$ Department of Pediatrics, Hamamatsu University School of Medicine,

Hamamatsu, Japan
}

results provide the first indication that $N D N F$ is a causative gene in $\mathrm{CHH}$. However, because there are no additional reports of $N D N F$ pathogenic variants in humans, the clinical significance of $N D N F$ abnormalities remains unclear.

In this study, we performed mutation screening of $N D N F$ in 61 Japanese patients clinically diagnosed with $\mathrm{CHH}$. This study was approved by the Institutional Review Board Committee at the National Center for Child Health and Development (\#512), and informed consent was obtained from the participants or their parents. The participants exhibited isolated normosmic $\mathrm{HH}(n=20)$, combined pituitary hormone deficiency (CPHD, $n=20$ ), Kallmann syndrome $(n=16)$, SOD $(n=4)$, or CHARGE syndrome $(n=1)$. Most of these patients were identified by delayed puberty, which is defined as the lack of pubertal signs at 15 years of age in males and at 13 years of age in females ${ }^{3}$, or by hypomasculinized external genitalia at birth. The remaining cases were diagnosed with $\mathrm{CHH}$ during endocrinological evaluations for CPHD, SOD, or CHARGE syndrome. Genomic DNA was extracted from peripheral blood samples. Prior to this study, sequence analysis of the nine major causative genes for $\mathrm{CHH}$ (ANOS1, CHD7, FGFR1, FGF8, GNRHR, GNRH1, KISS1R, $P R O K R 2$, and TACR3) was performed for all except for 13 (eight with CPHD, two with isolated normosmic HH, two with SOD, and one with Kallmann syndrome) cases ${ }^{4}$. The 48 participants were confirmed to carry no pathogenic variants in the nine genes. In the present study, we analyzed all coding exons (exons 2-4) and flanking intronic 
Table 1 NDNF variants identified in the present study.

\begin{tabular}{|c|c|c|c|c|c|c|c|c|c|c|}
\hline \multicolumn{3}{|l|}{ Variant } & \multicolumn{2}{|c|}{$\begin{array}{l}\text { Number of patients with the } \\
\text { variant }(n=61)\end{array}$} & \multirow[t]{2}{*}{$\begin{array}{l}\text { Allele frequency in the } \\
\text { general population }^{\mathrm{b}}\end{array}$} & \multirow[t]{2}{*}{$\begin{array}{l}\text { Functional } \\
\text { assessment }^{c}\end{array}$} & \multicolumn{4}{|c|}{ Effect on splicing } \\
\hline $\begin{array}{l}\text { Nucleotide } \\
\text { change }\end{array}$ & $\begin{array}{l}\text { Amino } \\
\text { acid change }\end{array}$ & $\mathrm{dbSNP}^{\mathrm{a}}$ & Homozygote & Heterozygote & & & $\mathrm{HSF}^{\mathrm{d}}$ & ASSP $^{e}$ & NNSPLICE $^{f}$ & SpliceRover \\
\hline c. $186 G>A$ & p.Lys62= & rs2276959 & 61 & 0 & 0.801 & 10.690 & No effect & No effect & No effect & No effect \\
\hline c. $429 C>T$ & p.Ser143= & rs3733560 & 16 & 29 & 0.520 & 1.401 & $\begin{array}{l}\text { Potential } \\
\text { alteration }\end{array}$ & No effect & No effect & No effect \\
\hline c. $435 A>G$ & p.Leu145= & rs3733559 & 2 & 28 & 0.188 & 1.083 & $\begin{array}{l}\text { Potential } \\
\text { alteration }\end{array}$ & $\begin{array}{l}\text { Cryptic } \\
\text { donor (5.80) }\end{array}$ & No effect & $\begin{array}{l}\text { Cryptic } \\
\text { donor }(0.30)\end{array}$ \\
\hline c.939T $>C$ & p.Asp313= & rs3822230 & 18 & 30 & 0.551 & 3.090 & No effect & No effect & No effect & No effect \\
\hline c. $1029 C>T$ & p.Val343= & rs145661282 & 0 & 1 & $4.395 \times 10^{-4}$ & 0.016 & $\begin{array}{l}\text { Potential } \\
\text { alteration }\end{array}$ & No effect & No effect & No effect \\
\hline c. $1035 \mathrm{~A}>\mathrm{G}$ & p.Leu345= & rs3733558 & 0 & 1 & $7.103 \times 10^{-6}$ & 0.067 & No effect & No effect & No effect & No effect \\
\hline c. $1035 A>C$ & p.Leu345= & rs3733558 & 20 & 28 & 0.547 & 0.057 & $\begin{array}{l}\text { Potential } \\
\text { alteration }\end{array}$ & No effect & No effect & No effect \\
\hline c. $1392 A>G$ & p.Ser464= & rs1397645 & 58 & 3 & 0.831 & 0.448 & No effect & No effect & No effect & No effect \\
\hline c. $1567 C>T$ & p.Leu523= & rs34766411 & 2 & 25 & 0.252 & 8.121 & $\begin{array}{l}\text { Potential } \\
\text { alteration }\end{array}$ & No effect & No effect & No effect \\
\hline
\end{tabular}

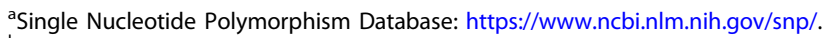

${ }^{\mathrm{b}}$ Genome Aggregation Database: https://gnomad.broadinstitute.org/.

${ }^{c}$ CADD: https://cadd.gs.washington.edu/.

dHSF: Human Splicing Finder: http://www.umd.be/HSF3/.

ASSP: Alternative Splice Site Predictor: http://wangcomputing.com/assp/. Default threshold: 4.50.

fNNSPLICE: http://fruitfly.org/seq_tools/splice.html. Default threshold: 0.40.

gSpliceRover: http://bioit2.irc.ugent.be/splicerover/. Default threshold: 0.10 .

sequences of $N D N F$ by direct sequencing. The primer sequences used are available upon request. Then, we referred to the gnomAD database (https://gnomad. broadinstitute.org/) to examine the allele frequencies of the identified variants in the general population. We also consulted the combined annotation-dependent depletion program (CADD; https://cadd.gs.washington.edu/snv), the Human Splicing Finder program (https://hsf. genomnis.com/home), the Alternative Splice Site Predictor program (http://wangcomputing.com/assp/), the NNSPLICE program (http://fruitfly.org/seq_tools/splice. html), and the SpliceRover program (http://bioit2.irc. ugent.be/splicerover/) to predict the effect of each variant on protein function and splice-site recognition.

Except for nine synonymous substitutions, we detected no variants in the coding exons or exon-intron boundaries of NDNF (Table 1). Of the nine variants, seven are common SNPs with allele frequencies in the general population of more than $10 \%$. The remaining two substitutions, NM_024574.4:c.1029C $>\mathrm{T}$ (p. Val343=) and c.1035A>G (p. Leu345=), are rare variants with allele frequencies in the gnomAD database of $4.395 \times 10^{-4}$ and $7.103 \times 10^{-6}$, respectively. The nine variants invariably showed low CADD scores and appeared to have negligible effects on splice-site recognition (Table 1). This suggests that all these variants are functionally neutral polymorphisms.

These findings indicate that NDNF pathogenic variants are uncommon among Japanese patients with $\mathrm{CHH}$. Our data are consistent with a previous report from Europe ${ }^{2}$. Thus, the contribution of NDNF variants to the etiology of $\mathrm{CHH}$ appears to be small. Notably, most of our subjects were confirmed to have no pathogenic variants in major known $\mathrm{CHH}$-causing genes; in these cases, $\mathrm{CHH}$ may have resulted from unique genetic or epigenetic abnormalities. Indeed, it is possible that several genetic factors involved in $\mathrm{CHH}$ remain undetermined.

Altogether, the results of this study, in conjunction with those of the previous study by Messina et al. ${ }^{2}$, indicate that pathogenic $N D N F$ variants are rare in $\mathrm{CHH}$ patients of both European and Asian descent. These data emphasize the genetic heterogeneity of $\mathrm{CHH}$.

\section{Acknowledgements \\ The authors thank the clinicians for providing clinical samples of the patients. This study was supported by grants from the JSPS (17H06428; 20H00539), AMED (20ek0109464h0001), the National Center for Child Health and Development (2019A-1), and the Takeda Science Foundation.}

\section{Author contributions}

M.F. designed the study. S.T., E.S., A.H., and Y.K-F. performed the sequence analysis. T.O. provided the clinical samples. S.T., M.F., and Y.K-F. drafted the manuscript. All authors read and approved the final version of this manuscript.

Conflict of interest

The authors declare that they have no conflict of interest.

\section{Publisher's note}

Springer Nature remains neutral with regard to jurisdictional claims in published maps and institutional affiliations.

Received: 19 October 2020 Revised: 4 November 2020 Accepted: 4 January 2021.

Published online: 2 February 2021 


\section{References}

1. Young, J. et al. Clinical management of congenital hypogonadotropic hypogonadism. Endocr. Rev. 40, 669-710 (2019).

2. Messina, A. et al. Neuron-derived neurotrophic factor is mutated in congenital hypogonadotropic hypogonadism. Am. J. Hum. Genet. 106, 58-70 (2020).
3. The MHLW study group for hypothalamic and pituitary dysfunction. The diagnosis and treatment guidelines for hypothalamic and pituitary dysfunction (in Japanese). Jpn. J. Endocrinol. 95(Suppl.), 1-60 (2019).

4. Topaloğlu, A. K. Update on the genetics of idiopathic hypogonadotropic hypogonadism. J. Clin. Res. Pediatr. Endocrinol. 9, 113-122 (2017). 